Association for Information Systems AIS Electronic Library (AISeL)

December 1999

\title{
Academic-Community Partnerships for Advanced Information Processing in Low Technology- Support Settings
}

Rosann Collins

University of South Florida

Follow this and additional works at: http://aisel.aisnet.org/amcis 1999

\section{Recommended Citation}

Collins, Rosann, "Academic-Community Partnerships for Advanced Information Processing in Low Technology-Support Settings" (1999). AMCIS 1999 Proceedings. 297.

http://aisel.aisnet.org/amcis1999/297

This material is brought to you by the Americas Conference on Information Systems (AMCIS) at AIS Electronic Library (AISeL). It has been accepted for inclusion in AMCIS 1999 Proceedings by an authorized administrator of AIS Electronic Library (AISeL). For more information, please contact elibrary@aisnet.org. 


\title{
Academic-Community Partnerships for Advanced Information Processing in Low Technology-Support Settings
}

\author{
Rosann Webb Collins \\ University of South Florida, 4202 East Fowler Avenue, CIS 1040, Tampa FL 33620-7800 \\ rcollins@coba.usf.edu
}

\begin{abstract}
The focus of this research is on knowledge workers in a particular kind of setting: not-for-profit community agencies that have low technology-support, but need to take full advantage of the power of advanced information technologies. Knowledge workers in these settings, given adequate assistance from a neutral agent and/or prototype applications, can successfully develop and use quite sophisticated information systems to enhance their work. The paper draws on case studies of knowledge workers in two community agencies who have partnered with academia, and identifies the specific information technology problems faced by community agencies, the source of these problems, and how the academiccommunity partnership can act to solve the problems.
\end{abstract}

\section{Introduction}

Knowledge workers in community service agencies have an increased need to be able to "gather and interpret data efficiently and effectively into functional information for professional acting social work settings" (Grebel and Steyaert, 1995, p. 163). These workers assume a variety of roles in community agencies, including administrators, program developers, counselors, and teachers. All would be categorized as knowledge workers because their tasks require non-routine and complex work, they must apply their knowledge capital to these tasks, their work requires significant cognitive information processing, and their written and verbal outputs have information content (Davis et al., 1993). Their needs for more information include content information to help community agency employees provide service to clients more effectively, information on community and other resources that can provide additional help for clients, as well as information that helps employees assess their service programs and the management of their agencies. These needs stem from both the desire to provide better service to clients and increased pressure from funding sources, public and private, for more accountability.

How can community service agencies meet these needs, when they are typically a low technology-support setting: staffed by professionals and volunteers with little information processing expertise beyond basic applications, with a small or no in-house information technology function, and with limited resources to purchase expertise and technology in the open market? One solution to this problem is to develop an academic- community agency partnership to develop needed systems, or to adapt a prototype system previously developed by one of these partnerships. This paper details the nature of the low technology-support setting of community agencies and how the academic-community partnership can act to solve the specific information technology challenges faced by community agencies. This research is based on two case studies in which the author is an active participant. One case study involves technology planning and the development of a data warehouse for enhanced program assessment at a publicly-funded crisis center in a metropolitan area of a large Southeastern state in the U. S. The second case study concerns the development of a program assessment system that combines a within-agency database and network with inter-agency data exchange; this system is for a charter school for children living in a privatelyfunded shelter for homeless families in the same area.

\section{What is Meant by Low-Technology Support Settings?}

Not-for-profit organizations that provide community services increasingly use information technology to capture data about their services and to support service delivery. Typically these systems are based on microcomputers and local area networks, and the systems include both standard personal productivity software and specialized software products for social service providers. For example, crisis center staff in the first case study use a suite of word processing, graphics, and spreadsheet programs, as well as a commercial product called IRIS, from Benchmark Enterprises, for client tracking and referral information support. Not all agencies have even basic information technology support, or what support they have is not evenly distributed throughout the agency. In the case of the charter school, the administrative office of the parent agency has a small MIS group that provides systems for administrative and development purposes. However, little information technology is supplied to the service components, such as the health clinic, counseling service and school, and the MIS group provides no support to non-administrative functional areas. In many community service agencies, system development and support are done by one or a few "power users" within the organization, by volunteers, by a small IS staff, and/or by outside consultants. Many community service agencies are therefore considered low technology-support settings. Despite this low level of 
support, users are able to accomplish a great deal when the technology solutions are well structured for their particular needs. However, users are typically unable, or less able, to create technological solutions for their problems using more advanced information technology resources.

\section{The Challenge: Meeting Knowledge} Workers' Needs with Low or No IT Support

Users in community agencies realize a need for more powerful applications of information technology. In addition they face increased pressure from government and other funding sources to provide and share better information about their operations. In particular there is a need to demonstrate program effectiveness and create information networks that can coordinate services across agencies. For example, both agencies studied are faced with a state mandate to provide cross-agency data on services to the homeless. However, there are several impediments to addressing such needs.

First, community agency knowledge workers may not fully understand the power of the technology they already possess. For example, in the case of the crisis center, some program evaluation reports could have been generated by the existing IRIS system, but the users thought they were limited to the reports designed by a consultant at initial implementation, and they do not have the training to design reports themselves. Complicating this particular point is that the users may also lack knowledge of exactly how to process the information as requested. For example, in both cases individuals expressed a need to provide longitudinal data analyses to their funding or government agencies. Neither agency had staff with the statistical expertise to adequately set up such analyses, even if they had access to the data and the data analytic tools.

Second, knowledge workers in community agency users are likely to have some, but not all the technology expertise they need to create solutions with advanced technologies such as data warehouses and inter-agency networks. For example, research by Grebel and Steyaert (1995) indicates that in almost all European Community countries, the curriculum for social workers includes at least basic computer literacy. However, many schools do not have adequate resources for building knowledge on how to integrate IT applications into social work, and in general there is a "gap between the education of new social workers and requirements of today's profession" (p. 162). Using information technology for assessment of services through analysis of data aggregations and data sharing across agency, while needed, may seem impossible for community agency professionals who lack IT education. Even what an IS professional might consider basic procedures, such as regular data and system backup with off-site storage, may not be done in some community agencies because of lack of training.
Third, the knowledge workers in community agencies may feel at a disadvantage in negotiating for assistance in addressing information technology needs. Managers at both agencies studied reported bad experiences with consultants (expensive and not very responsive); the MIS staff of other, larger organizations (unwilling to help create data exchanges); and volunteer help from local companies (not fully committed for long term assistance). This is also a problem when, as discussed earlier, there are needs for help in deciding what data is to be analyzed and how it should be analyzed or processed, as well as in developing or acquiring information technology to support that analysis. Finding IS consultants, MIS staff from parent organizations, or volunteers who combine both sets of expertise is difficult, and if such help is not voluntary, it is expensive.

Fourth, knowledge workers in community agencies find it difficult to get funding for information technology projects if they cannot articulate exactly what is needed and why it is necessary for the agency programs. In the crisis center agency case, the academic partnership began with a technology assessment of the agency's existing and needed technology infrastructure (hardware, software, data, networks, expertise) that was done by an advanced systems analysis and design class under the supervision of the author. This agency had already been turned down for one grant for additional information technology because they could not demonstrate what existing computer systems were available or what they needed. This agency had a particular problem in that they had grown over time as the county government merged ten other, smaller agencies with the crisis center. No one had ever attempted to document the technology infrastructure of this new, larger agency, nor had they taken any action to standardize on common application suites or platforms. One part of the assessment document modeled common data, processes, software, hardware, and networks, and described a plan for moving all areas within the agency to standard applications, platforms and data. Once the technology assessment document was prepared it was used to support successful funding requests from both a government agency and a local company.

\section{The Win-Win Nature of the Academic- Community Partnership}

The academic-community partnership provides benefits to both the community agencies as well as to the academic partners who provide the assistance, resulting in a real "win-win" situation.

The academic-community partnership does not replace assistance from the IT marketplace, but rather helps knowledge workers be wiser users of existing technologies and consumers of new technologies. The argument for an academic-community partnership that assists knowledge workers in community agencies in developing advanced uses of information technology is that expert academic help can: 
a) assess the current information technology capabilities (hardware, software, networks, data, skills) of the agencies, so that users understand the power of their existing tools as well as how to enhance them through training and acquisition. This is particularly important when the best solution is not to simply buy more hardware, but rather use what they have more effectively. If an agency is using a consultant who benefits financially when new hardware or software is acquired or developed, then it is unlikely a consultant will focus on a lower-cost solution.

b) provide training and support where that is not available in the marketplace. Again, this training is likely to go beyond the use of an information technology, and into training on what data processing/analyses are needed for a task. Academics who combine expertise in both technology and common data analytic procedures are able to provide both kinds of training and support.

c) serve as a communication bridge between the marketplace of information technology or the MIS staff of other, larger organizations and the community agency, so that agency mangers do not feel at a disadvantage in negotiating for services and products or for common systems; and

d) create structured solutions, in the form of prototypes that can be adapted in many agencies. Much of the base technology employed by community agencies is widely used: general-purpose products like Microsoft Office, as well as specialpurpose products like IRIS (which is used throughout the U.S. for crisis center-type agencies). The idea is to leverage this fact by creating procedures and designs that can be valuable to many communities. The prototypes include not just the technology solution for a particular agency, but also the processes and procedures necessary for creating the solution in most/many low technology-support settings. The prototypes may be critical for agencies located in areas where there are few or no IT professionals in academia or business who are willing to provide direct assistance. In Australia Rochester and Willard (1998) found that all community groups realized a need for information to pursue their goals, but groups in rural areas sometimes felt disadvantaged in their access to information. The next phase of this research will examine how well knowledge workers in other community agencies can take advantage of one or more prototype solutions created for the two case study agencies.

In addition to these benefits, the partnership also helps knowledge workers who serve as academic partners. For example, a successful academic-community agency partnership developed a community information network for Decatur Illinois. This project used students from the local university for tasks such as Web page design, preparation of documentation, and analysis of legal issues in information distribution. The project director notes the "win-win nature of the partnership, since it provides a "benefit [to] the student's educational experience and [fills] the agency's need for volunteer help in the networking area" (Hale, 1996, p. 205).

Two examples from the author's own experience reiterate this point. Recently Arthur Andersen has been supporting competitions in which university student teams from MIS and computer science departments design web pages for local community agencies who lack the expertise to create high quality web pages for themselves or the funds to pay someone for this work. Even in cases where the student team designs just the opening web pages, these serve as a template design that can be built upon more easily by the agency staff or consultants. Similarly the advanced systems analysis and design students who completed the technology assessment project had to work in teams to interview users, examine computer equipment, create models, sythesize models across teams, and present results both orally and in written form. The students get valuable experience dealing with, as one student put it, "real users" and real problems. They get to practice fundamental systems development and assessment techniques, and at the end they have a nice work sample to show employers.

\section{References}

Davis, G. B.; Collins, R. W.; Eierman, M. A. and Nance, W. D. "Productivity from Information Technology Investment in Knowledge Work." in Strategic Information Technology Management, edited by R. D. Banker, R. J. Kauffman, and M. A. Mahmood. Harrisburg PA: Idea Group Publishing, 1993, pp. 327 -343 .

Grebel, H. and Steyaert, J. "Social Informatics: Beyond Technology: A Research Project in Schools of Social Work in the European Community." International Social Work (38), April 1995, pp. 151-164.

Rochester, M. and Willard, P. "Community Organizations and Information: Results of a Study." The Australian Library Journal, (47: 3) August 1998, pp. 254-263.

Hale, C. "'Project MILLIKInet' Becomes 'DecaturNet': A Library-Initiated Community Information Network." Illinois Libraries, (78: 4) Fall 1996, pp. 201-210. 